\title{
A Case Report-Fibrous Dysplasia of Temporal Bone
}

\author{
Amit Saini, Rajender Parshad and Munish Kumar Saroch* \\ ENT Dr. RPGMC Kangra at Tanda (HP), India
}

*Corresponding author: Munish Kumar Saroch, , India

Submission: 韭 August 31, 2017; Published: 海 November 13, 2017

\begin{abstract}
We present a case of 35 year old female with monotonic fibrous dysplasia which presented to us with blocked sensation, impaired hearing, and Discharge right ear with mass in the right mastoid region for the last one year. Main complaint of the patient was decreased hearing and found to be conductive hearing loss. Computed tomography showed diffusely expanded right temporal bone/mastoid, petro us parts and EAC with increased bone density. Patient underwent surgery for contouring of bone and canalplasty which improved hearing status, blocking sensation and discharge completely. Although there was cosmetic deformity but patient was not concerned regarding that, which also improved. Patient is under regular follow-up with very good functional and cosmetic results. From his case report, we learn the importance of conservative surgery and regular follow up in few selective cases of temporal bone fibrous dysplasia.
\end{abstract}

Keywords: Fibrous dysplasia; Temporal bone; Contouring of bone

\section{Introduction}

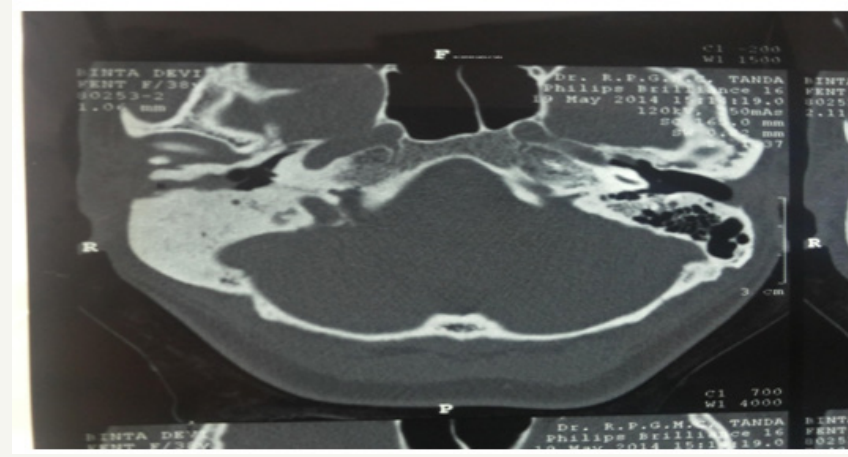

Figure 1: Showing fibrous dysplasia right mastoid bone.

Fibrous dysplasia consists of fibrous tissue, bony spicules that are undergoing resorption and formation and islands of cartilage replacing bone marrow, it generally leaves the cortex intact. They are slow progressive and benign fibro osseeous disorders of unknown etiologic [1]. Von Recklinghausen first recognised fibrous dysplasia as a clinical entity in 1891 although prehistoric and angloascian specimens have been identified [2]. The term fibrous dysplasia was first used by Lichtenstein in 1938, although it was described by McCone and Branch in 1937. There are monotonic and polyostotic forms, the latter exemplified by McCone Albright syndrome (polyostotic fibrous dysplasia with precocious sexual development). Monotonic variant accounting for $70 \%$ of the cases. There is rarely involvement of temporal bones in fibrous dysplasia but when it occurs it usually presents typically with impaired conductive hearing loss, blocking sensation in concerned ear (Figure 1). Stenos is of EAC5-7. We report a case of monostotic
Fibrous dysplasia involving the temporal bone in which impaired hearing, blocking sensation in ear and discharge from ear are presenting complaints [3].

\section{Case Report}

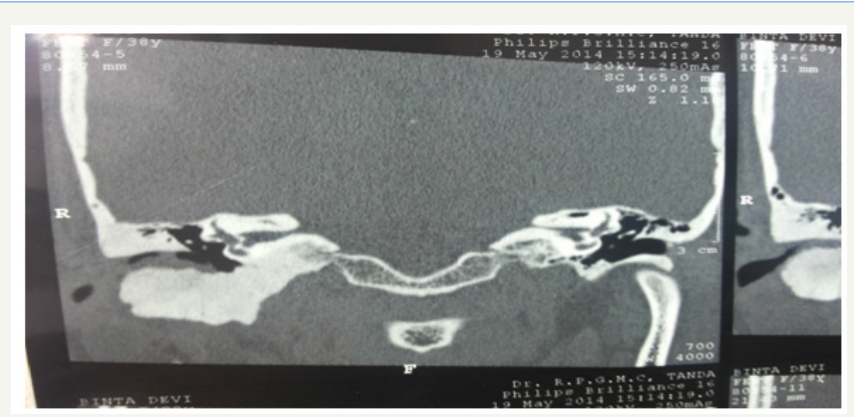

Figure 2: Showing fibrous dysplasia right mastoid bone.

A 38 years old female presented was referred from zonal hospital to our outpatient department with blocked sensation, decreased hearing and discharge from the ear since 1month. Patient was apparently well 1year back when she developed blocking sensation right ear which was gradual in onset slowly progressive. She also had decreased hearing from same duration, gradual onset slowly progressive. $\mathrm{H} / \mathrm{O}$ discharge right ear for the last 1 month. Discharge was yellowish, scanty, sometimes watery and sometimes thick (viscid), foul smelling and blood tinged for the last one month. There was also pain mild to moderate, intermittent for the last one month. Female was concerned regarding hearing/ blocking sensation and discharge. There was no H/O Vertigo, tinnitus or facial weakness. On examination. Pinna was normal in 
position and size [4]. There was dermatitis in post auricular region (Figure 2). Tragal sign and circumduction sign were negative. Right external auditory canal was obliterated by mass reddish in colour seeming to arise from the posterior canal wall. On probing the swelling of external auditory canal was slight tender, does not bleed on touch seem to be arising from the posterior canal wall and floor of the external auditory canal. Otoscopy revealed a markedly narrow external auditory canal on right side compared to left. Rest of general physical and systemic examination were normal [5].

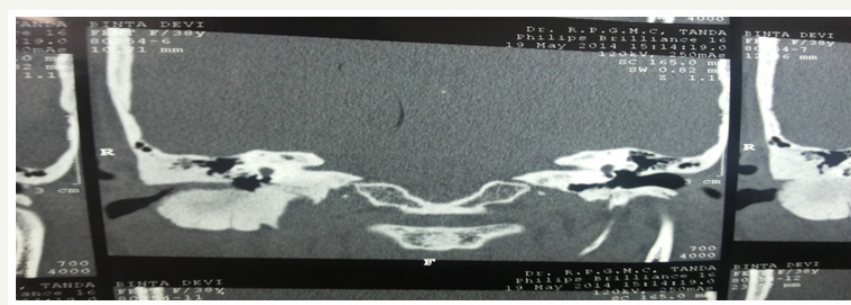

Figure 3: Showing fibrous dysplasia right temporal bone with petro us part involvement.

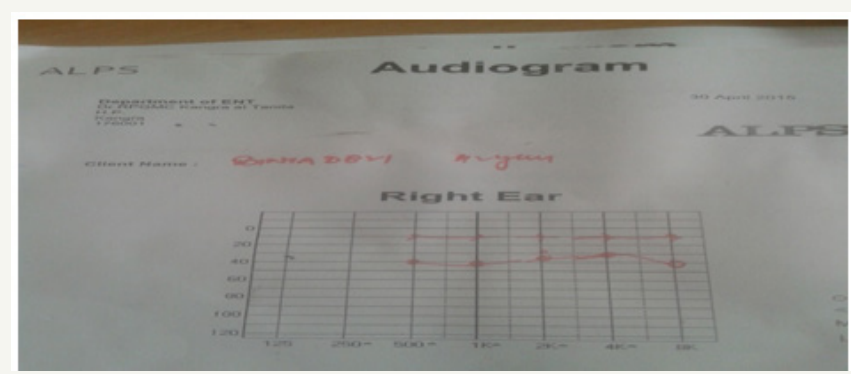

Figure 4: Showing moderate conductive hearing loss preoperatively.

CT temporal bone revealed diffuse expansion of right temporal bone with generalised increased in bone density. The changes were involving the mastoid, petrous part as well as bony EAC. The expansion was causing narrowing of external auditory canal. No any abnormal soft tissue mass overlying the temporal bone. There was a focal protuberance in the right mastoid process. The EAC is also filled with non enhancing tissue. The tympanic membrane was retracted. Right middle ear cavity was well pneumatised and there is no soft tissue mass (Figure 3). Bilateral ossicular chain and inner ear structures are normal. Left side was also normal. Both facial nerves normal. Intracanalicular, labyrinthine, tympanic and mastoid parts normal. There was no abnormal enhancement after IV contrast administration [6]. Pure tone audiometry showed moderate conductive hearing loss in the right ear with normal hearing left ear. There was homogenously increased ground glass density and trabecular pattern. A biopsy was taken from the mastoid region which in histopathology examination showed irregularly shaped trabeculae of the bone in cellular fibrous stoma consistent with the diagnosis of fibrous dysplasia. All other biochemical tests were normal. The patient was concerned about blocking sensation, decreased hearing and discharge but no cosmetic deformity. Surgery was planned by post auricural approach. Partial resection and contouring of bone from posterior canal wall and floor of EAC was done with fissured and diamond burrs (Figure 4). After the bone was removed there was found epithelial debris in the external canal and was cleaned. Post auricular incision was closed in layers and EAC was packed with antibiotic soaked pack. Post operative period was uneventful and was symptom free during follow-up period $[7,8]$.

\section{Discussion}

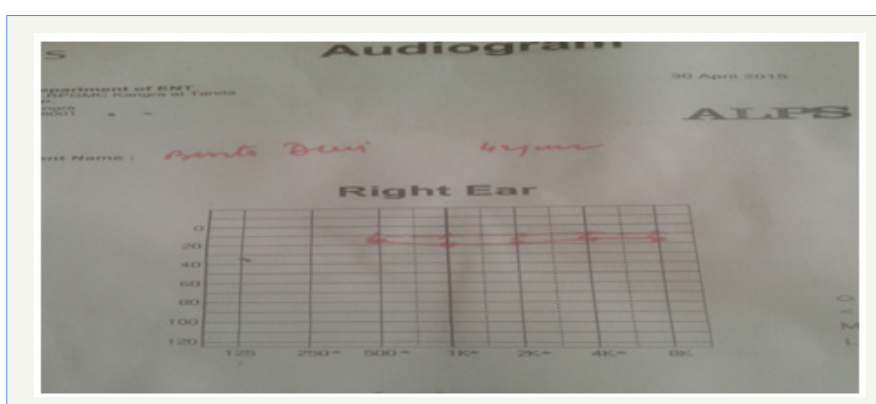

Figure 5: Showing normal hearing postoperatively.

Fibrous dysplasia is genetic but non familial disorder encompassing a wide range of phenotypes, including skeletal deformity, neurological compromise and endocrinology dysfunction. Early workers believed it to be caused by the arrest of bone at an immature stage of development or a disturbance of bone maintenance and turnover8. The actual cause has recently been defined as a set of post zygotic messenger mutations in the GNASI gene located on chromosome 20q13.2 that normally codes for the alpha subunit of the Gas second- messenger protein $[9,10]$. GSx is ubiquitous heterotrimeric G-Protein responsible for linking cell surface receptors to the effectors enzyme adenylyl cyclise, promoting intracellular generation of cyclic adenosine monophosphate (CAMP) [11]. Fibrous dysplasia develops as a result of abnormal growth and differentiation of marrow stomas cells [12], with the mutation stimulating proliferation and inhibiting differentiation of bone progenitor partially through camp Dependent activation of C-fos gene [13]. The Male: female ratio for the disease in general is equal [14], but among younger patients males are suffering more [15]. Although there are 3 types- monostotic, polyostotic and polyostotic with endocrinal abnormalities (Mccune-albright syndrome). The temporal bone is involved in $10 \%$ of the cases $[5,7]$ and monostotic form is the most common present in $70 \%$ of the cases. The most common complaint of the patient suffering with fibrous dysplasia of temporal bone is progressive hearing loss, usually conductive, although $17 \%$ have sensor neural hearing loss. Involvement of middle ear structures including erosion of the optic capsule, ossicles or fallopian canal can lead to labyrinthitis or, in $10 \%$ of the patients, facial palsy [6]. Patients may also complain of palatial tinnitus, otalgia or otorrhoea. Clinical and CT findings suggested a diagnosis of fibrous dysplasia which was confirmed by biopsy and HPE findings. Fibrous dysplasia diagnosis is routinely made on the basis of clinical grounds (Figure 5). The differential diagnosis includes: Eosinophilic granuloma, Aneurysmal bone cyst, Giant cell reparative granuloma, Osteoblastoma, Meningioma, Osteoma, Osteosarcoma, Paget's disease, Otosclerosis, Osteogenesis imperfect, Osteopetrosis, Metastatic disease and Hemangioma. Surgical biopsy allows histologic examination of the tissue revealing lesions made of mesenchymal cells with the general appearance of 
spindle shaped fibroblats [16]. The diagnosis of fibrous dyplasia is confirmed with a combination of radiographic and histopathologic data.

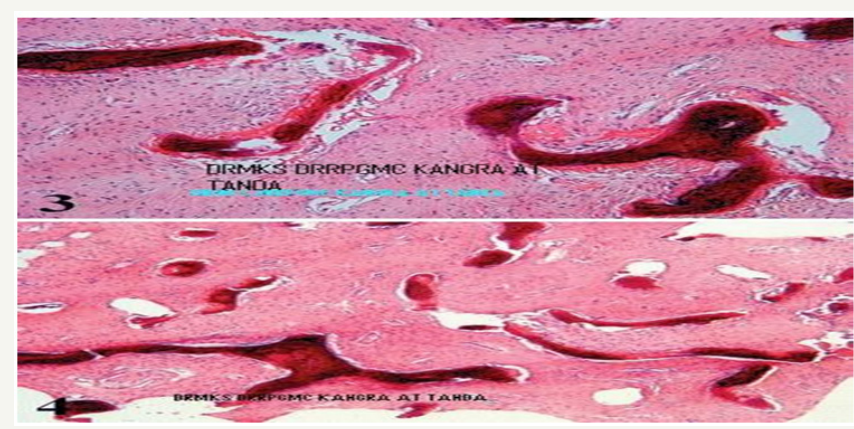

Figure 6: Showing histopathological changes in fibrous dysplasia Mainly Irregularly Shaped Trabeculae of the Bone in Cellular Fibrous Stroma Consistent with the Diagnosis of Fibrous Dysplasia.

There are three classic patterns of radiologic features of fibrous dysplasia of skull base and facial bones. The planetoid/ ground glass pattern is most common $56 \%$, Sclerotic $23 \%$, Cystic $21 \%$. This patient is having sclerotic variety. CT findings are path gnomic and also aid in monitoring the progress of the disease [17]. Furthermore computerised tomography is very important in making differences between fibrous dysplasia and osteodystrophies of the skull base including otosclerosis, osteogenesis imperfecta, Paget's disease, osteopetrosis, haemangioma, meningioma and mucocele $[18,19]$. CT can identify typical ground glass appearance of the lesions assymetry of the skull with thickening of the cranial cortex involvement of the particular cranial bones and the presence of cystic changes [14]. Bio phosphates as medical treatment have been shown to reduce bony pain and incidence of fractures $[20,21]$. Surgery is done usually for cosmetic or functional reasons [22]. With surgical treatment offering only hope of cure although decision to operate in areas commonly affected such as the skull base requires a careful comparison of the morbidity caused by surgical resection and that caused by the disease itself [23]. Pathologic bone is spongy and soft and is easily curetted away, although recurrences are common. A subtotal resection in the vicinity of critical structures is acceptable. A Definitive indication for surgical intervention in fibrous dysplasia of the temporal bone by an ENT surgeon is stenosis of the external auditory with collection of epithelial debris between tympanic membrane and dysplasia mass blocking external auditory canal [24]. In Present case intervention was done for widening of the external auditory canal as patient was having moderate conductive hearing loss with collection of epithelial debris leading to blocking sensation and discharge from the ear (Figure 6). We did not perform the prophylactic decompression of the facial nerve as has been recommended in the literature [25]. Malignant transformation in fibrous dysplasia is very rare and is only $0.4 \%$ of patients. Radiation treatment is best avoided because of [10] fold increase in the likelihood of sarcomata's transformation [5]. On an average 13.5 years pass between the diagnosis and progression to osteosarcoma, fibrosarcoma, chondrosarcoma or giant cell sarcoma. The risk is however 10 times in patients with McCone Albright syndrome and 100 times in irradiated patients [26]. In patients where no definitive surgical indication exists, interval CT scans have been recommended to determine the rate of growth of lesion.

\section{Conclusion}

Fibrous dysplasia of temporal bone and skull base is a benign disorder with only $0.4 \%$ malignant transformation. Computerised tomography is the diagnostic modality and histopathology further confirms it. Surgery in the regions adjoining vital structures should be reserved for patients with definitive functional impairment and visible disfigurement. Further unilateral resection in vicinity of the critical areas is an acceptable option.

\section{References}

1. Fakhri S, Levantal M, Rochon L (2003) Fibrous dysplasia of the temporal bone. J Otolaryngol 32: 132-135.

2. Recklinghausen FV (1891) Die fibrose oder deformierende ostitis die osteomalacir and die osteoplastische carcinose in ihren gegen seitigen Beziehungen In: Festschrift Rudolf Virchow 1891 Berlin. Georg Reimer.

3. Lichtenstein L (1938) Polyostotic fibrous dysplasia. Arch Surg 36(5): 874-898.

4. Tochina R, Sunami K, Yamane H (2004) Fibrous dysplasia of the temporal bone with cholesteatoma. Acta Otolaryngol (554): 47-49.

5. Nager GT, Kennedy DW, Kopstei E (1982) Fibrous dysplasia: A review of the disease and its manifestations in the temporal bone. Ann otol Rhinol Laryngol Suppl 92: 1-52.

6. Megerian CA, Sofferman RA, McKenna MJ (1995) Fibrous dysplasia of the temporal bone: Ten new cases demonstrating the spectrum of otologic sequelae. Am J Otol 16(4): 408-419.

7. Windolz F (1947) Cranial manifestations of fibrous dysplasia of bone. AJR Am J Roentgenol 58: 51-63.

8. Reed R (1963) Fibrous dysplasia of bone a review of 25 cases. Arch Pathol 75: 480-495.

9. Shenker A, Weinstein LS, Moran A (1993) Severe endocrine and nonendocrinemanifestations of Mccune-albright syndrome associated with activating mutations of stimulatory G protein GS. J Pediatr 123(4): 509-518.

10. Weinstein LS, Chen M, Liu J (2002) Gas mutations and imprinting defects in human diseases. Ann N Y Acad Sci 968: 173-197.

11. Bianco P, Robey PG (1999) Diseases of bone and the stromal cell lineage. J B M R 14(3): 336-341.

12. Candeliere GA, Glorieux FH, Prudhomme J (1995) Increased expression of the c-fos proto oncogene in bone from patients with fibrous dysplasia. N Engl J Mwd 332(23): 1546-1551.

13. Lustig LR, Holiday MJ, Mccarthy EF (2001) Fibrous dysplasia involving the skull base and temporal bone. Arch Otolaryngol Head Neck Surg 127(10): 1239-1247.

14. Levine MA (1999) Clinical implications of genetic defects in G protein: Oncogenic mutations in Gas as the molecular basis for the McCone Albright syndrome. Arch Med Res 30(6): 522-531.

15. Spujt H, Dorfman H, Fechner R (1970) Tumours of bone and cartilage: Atlas of tumour pathology. Washington (DC): Armed forces institute of pathology.

16. Greco MA, Steiner GC (1986) Ultrastructure of fibrous dysplasia of bone: A Study of its fibrous, osseous and cartilagenous components. Ultrastruct Pathol 10(1): 55-66.

17. Reddy KTV, Vinayak BC, Jefferis AF (1994) Fibrous dysplasia of the temporal bone. Ann Otol Rhinol Laryngol 103: 74-76.

18. Casselman JW, De jonge I, Neyt I (1993) MRI in craniofacial fibrous dysplaia. Neuroradiology 35(3): 234-237. 
19. Brown EW, Megerian CA, McKenna MJ (1995) Fibrous dysplasia of the temporal bone. Imaging findings. AJR Am J Roentgenol 164: 679-682.

20.Zacharin M, O’Sullivan M (2000) Intravenous Pamidronate treatment of polyostotic Fibrous dysplasia associated with Mccune-albright syndrome. J paediatr 137(3): 403-409.

21. Lala R, Matarazzo P, Bertelloni S (2000) Pamidronate treatment of bone fibrous dysplasia in nine children with Mccune-albright syndrome. Acta paeditr 89(2): 188-193.

22. Gungor A, Cincik H, Colak A (2003) Fibrous dysplasia involving the temporal bone: Report of four cases. The internet journal Otorhinolaryngology 2(1).
23. Maher CO, Freidman JA, Meyer FB (2002) Surgical treatment of fibrous dysplasia of the skull in children. Paediatr Neurosurg 37(2): 87-92.

24. Morrissey DD, Talbot JM, Schleuning AJ (1997) Fibrous dysplasia of the temporal bone: Reversal of sensorneural hearing loss after decompression of the internal auditory canal. Laryngoscope 107(10): 1336-1340.

25. Chen YR, Breidahl A, Chang CN (1997) Optic nerve decompression in fibrous dysplasia: Indications, efficacy, and safety. Plast Rerconstr Surg 99(1): 22-30.

26. Ruggeire P, Sim FH, Bone JR (1994) Malignancies in fibrous dysplasia. Cancer 73(5): 1411-1424. 